\title{
Public Attitudes to the Disease Concept of Alcoholism
}

\author{
John Crawford/ MSc \\ Department of Psychology \\ University of Aberdeen \\ Nick Heather, PhD \\ Addictive Behaviours Research Group \\ Department of Psychiatry University of \\ Dundee
}

\begin{abstract}
Proponents of the disease concept of alcoholism have argued that its dissemination among the general public will promote humanitarian attidues toward alcoholics. This claim was subjected to empirical scrutiny. A quota sample of 200 members of the general public completed a questionnaire designed to measure beliefs about alcoholism and attitudes toward alcoholics. As predicted, the majority of respondents endorsed a disease formulation. However, examination of the data using correlational and factor analytic techniques indicated that two humanitarian views - expressing sympathetic attitudes toward alcoholics and regarding them as deserving of public funds - were largely independent of endorsing a disease view.
\end{abstract}

*To whom requests for reprints, the questionnaire used, and a fuller version of this paper should be sent at the Department of Psychology, University of Aberdeen, Aberdeen AB9 2UB, U.K. 


\section{INTRODUCTION}

Proponents of the disease concept of alcoholism have long maintained that it constitutes a powerful or even essential tool for the promotion of humanitarian attitudes toward alcoholics. This assumption has seldom been questioned and even leading critics of the disease concept appear to endorse it. For example, Kendell (1979) has stated: "In many ways the practical consequences of this concept have been beneficial. Public attitudes to alcoholics... are far more humane that they were a generation ago" (p. 367). Some authors have gone so far as to argue that the disease concept should not be viewed as an explanatory concept but purely as a vehicle for promoting positive societal attitudes. An example of this position, which Room (1972, p. 1056) has termed "humane cynicism," is provided by Pattison (1969) when he states that "the major advantage of defining alcoholism as a disease is social. ... To say that alcoholism is an illness should not be considered as a statement about the etiology or treatment of alcoholism" (p. 953).

This study was not concerned with the specific implications for treatment of various types of disease model, nor with formal or informal policies for intervention with alcoholics, but only with the wider impact of the disease view of alcoholism among the general public. The main aim was to subject the assumption that the disease concept promotes humanitarian attitudes to empirical scrutiny by means of a questionnaire completed by members of the public. The full aims were as follows:

1. To measure the current degree of acceptance a disease/illness conception of alcoholism commands among the general public in Britain. American public attitudes research has supported Jellinek's (1960) statement that "In Amer ica we may speak of a majority acceptance of the illness conception of alco holism" (p. 8). Haberman and Sheinberg (1969), for example, reported that $64 \%$ of their respondents endorsed a disease conception, while in a study by Mulford and Miller (1964) the figure was $65 \%$. Are these results paral leled in the UK?

2. To examine the relationship between endorsement of the disease and the moral weakness conceptions of alcoholism. The educational effort launched by proponents of the disease concept had been intended to replace the pre vailing moral conception of alcoholism with a disease conception (Keller, 1976). However, although the evidence suggests that they have been success ful in inculcating the disease concept in the public mind, the expected corresponding decline in moral conceptions does not appear to have oc curred (Room, 1983). Thus, Mulford and Miller (1964) reported that 75\% of their sample defined the alcoholic as "morally weak" or "weak-willed" while "fully $41 \%$ of the sample defined the alcoholic as both morally weak 
and ill" (p. 316). In two studies (Orcutt, 1976; Room, 1972) endorsement of moral weakness statements was more common in respondents who endorsed a disease conception than in those who rejected it.

3. To investigate the relationship between social desirability and endorsement of a disease/illness conception. Some commentators (e.g., Haberman and Sheinberg, 1969) on the attitudes literature have expressed the view that the public pay only "lip service" to a disease conception. This view is sup ported by Tolor and Tamerin's (1975) demonstration of a significant posi tive correlation between endorsing the disease view and social desirability as measured by the Marlowe-Crowne Social Desirability Scale (Crowne and Marlowe, 1960). This finding suggests that the public may endorse a disease view to appear well informed or because they believe it to be the most prestigious reply. It is difficult, however, to assess the extent to which Tolor and Tamerin's findings are a true reflection of the situation in the general pop ulation since their sample was very restricted in terms of demographic varia bles, being confined .entirely to (predominantly female) college graduates.

4. As previously stated, the principal aim was to investigate the relationship between endorsement of a disease conception and expression of humanitari an attitudes toward alcoholics.

\section{METHOD}

Two hundred members of the general public completed the Attitudes and Beliefs About Alcoholism and Alcoholics Questionnaire, which is detailed in Table 1. Preliminary pilot work was carried out with a series of general openended questions. Subjects $(n-32)$ were randomly selected on a door-to-door basis. In combination with a perusal of previous attitude research (Marcus, 1963; Tolor and Tamerin, 1975), this formed the basis for the construction of a series of attitude statements. Further pilot work ( $n$ - 34) was carried out with these attitude statements. Items were discarded if they demonstrated appreciable ceiling or floor effects, or if they yielded a high number of "undecided" responses. This pilot work allowed construction of the final questionnaire. In an attempt to minimize the potential biasing effects of the order of item presentation, the orders of presentation for Sections I, II, and HI were reversed in half the questionnaires.

As the intention was to recruit a representative cross-section of the population aged between 18 and 65, census figures were used to derive sampling matrices based on Sex X Age X Social Class and Sex X Age X Marital Status. The questionnaires were distributed in Dundee during 1981-1982 on a door-todoor basis and collected at a later date. Subjects were initially recruited on a random basis. As they were recruited, subjects were classified by demographic characteristics and assigned to the relevant cell of the matrix. This allowed any 
Table 1

Summary of the Attitudes and Beliefs About Alcoholism and Alcoholics Questionnaire

The questionnaire consists of six sections, with Sections 1 to 3 consisting of attitude statements to which respondents indicated the extent of their agreement or disagreement on a 5-point scale ranging from "strongly disagree" (1) to "strongly agree" (5).

\section{Section 1: Conceptions of Alcoholism}

a. Disease conception-"Alcoholism is best seen as a form of disease or illness."

c. Sin conception-"Alcoholism is best seen as a form of wrongdoing." b. Habit/nondisease conception-"Alcoholism is best seen as a form of habit, not disease.

d. Alcoholism as akin to drug addiction"Alcoholism is best seen as a form of drug addiction, like heroin addiction."

Section 2: Etiology of Alcoholism

a. Physical etiology -"The causes of alcoholism lie more in the body than in the mind."

b. Moral weakness etiology-"People become alcoholics because of moral weakness."

c. Inadequacy etiology - "People become alcoholics because they have weak, inadequate personalities."

d. Hereditary etiology-"The causes of alcoholism lie in the physical makeup some people are born with."

e. Psychosocial etiology-"People become alcoholics because of unhappiness with their life, marriage, or job."

Section 3

Section 3 measured attitudes to alcoholics in terms of the extent to which they were perceived as deserving of sympathy and publicly funded intervention. Items were combined to provide a composite Attitudes Index.

a. "Alcoholics deserve public money for the provision of help."

c. "Money to help alcoholics should only be provided very sparingly." b. "A lot of people nowadays seem to have a wishy-washy, oversympathetic view of alcoholics."

d. "Alcoholics deserve more sympathy than they receive at present."

Section 4

Section 4 contained a short form (7-item) of the Crowne and Marlowe (1966) Social Desirability Scale. This was obtained by piloting the full scale with 35 subjects. Those individual items which showed the highest correlation with total score were selected.

Section 5

Section 5 recorded personal details of the respondents-age, sex, marital status, occupation, estimates of weekly alcohol consumption, and the extent of personal contact with alcoholics. 
discrepancies between the sampling matrix and the sample to be monitored. As discrepancies become marked, an attempt was made to selectively recruit. Inevitably, as the desired number was approached, questionnaires were returned by subjects who fell into a cell of the matrix which already had its full allocation. These questionnaires were discarded. The initial refusal rate was $7.8 \%$. Questionnaires could not be retrieved from three individuals.

\section{RESULTS}

As Table 2 indicates, the majority of respondents $(69.5 \%)$ endorsed a disease/illness conception of alcoholism, and $27.5 \%$ of subjects endorsed the "moral weakness" etiology item. Only $20 \%$ of respondents endorsing a disease concept simultaneously endorsed the moral weakness item, whereas $44 \%$ of those rejecting a disease conception endorsed this item. Thus, endorsing a disease conception tends to be associated with rejection of moral weakness views. This was also illustrated by the modest but significant negative correlation (Pearson product-moment) between disease and moral weakness items $(r=$ $0.22, p<0.001)$.

No statistically significant correlations were obtained between social desirability and responses to items measuring conceptions of the nature and etiology of alcoholism and attitudes to alcoholics (Sections I to III). It can be seen from Table 3 that a positive correlation $(r=0.19)$ exists between endorsing a disease conception and endorsing sympathetic attitude statements on the Attitudes Index. However, the correlation is small (shared variance $=3.6 \%$ ), and thus endorsement/rejection of a disease conception is a poor predictor of attitudes toward alcohlics. As Table 3 shows, other items are better predictors of attitudes to alcoholics. Most notably, a correlation of -0.58 exists between the Attitudes Index and the moral weakness item.

Because of the large number of variables involved in this study, it was felt that data reduction techniques would be useful to help elucidate the relation-

Table 2

Distribution of Subjects' Responses to "Conceptions of A/coholism" /tems (Section I)

\begin{tabular}{lcc}
\hline Conceptions & Disagree and undecided, \% & Agree, \% \\
\hline Alcoholism as "habit" & 61.0 & 39.0 \\
Alcoholism as "drug addiction" & 24.5 & 75.5 \\
Alcoholism as "sin" & 93.5 & 6.5 \\
Alcoholism as "illness/disease" & 30.5 & 69.5 \\
\hline
\end{tabular}


Table 3

Correlations (Pearson Product-Moment) Between Conceptions and Etiology of Alcoholism Items and Scores on the Composite Index of Attitudes Toward Alcoholics

\begin{tabular}{|c|c|c|c|c|c|}
\hline \multicolumn{6}{|c|}{ Conceptions } \\
\hline & Alcoholism as "habit" & $\begin{array}{l}\text { Alcoholism as "drug } \\
\text { addiction" }\end{array}$ & Alcoholism as "sin" & $\begin{array}{l}\text { Alcoholism as illness/ } \\
\text { disease }\end{array}$ & \\
\hline $\begin{array}{l}\text { Attitudes to Alcoholics } \\
\text { Index }\end{array}$ & $\begin{array}{l}r=-0.29 p \\
<0.001\end{array}$ & $\begin{array}{l}r=0.04 \\
\mathrm{NS}\end{array}$ & $\begin{array}{l}r=-0.43 p \\
<0.001\end{array}$ & $\begin{array}{l}\mathrm{r}=0.19 p< \\
0.005\end{array}$ & \\
\hline \multicolumn{6}{|c|}{ Etiologies } \\
\hline & Psychosocial etiology & Physical etiology & Inadequate personality & Hereditary etiology & $\begin{array}{l}\text { Moral weakness } \\
\text { etiology }\end{array}$ \\
\hline $\begin{array}{l}\text { Attitudes to Alcoholics } \\
\text { Index }\end{array}$ & $\begin{array}{l}r=0.02 \\
\mathrm{NS}\end{array}$ & $\begin{array}{l}/ \bullet=0.0 \mathrm{i} \\
\mathrm{NS}\end{array}$ & $\begin{array}{l}r=-0.41 p \\
<0.001\end{array}$ & $\begin{array}{l}\mathrm{r}=0.13 \\
\mathrm{NS}\end{array}$ & $\begin{array}{l}/ \bullet=-0.58 p \\
<0.001\end{array}$ \\
\hline
\end{tabular}


Table 4

Factor Structure

\begin{tabular}{lccccc}
\hline & $\begin{array}{c}\text { Factor 1 } \\
(43 \%)^{\mathrm{a}}\end{array}$ & $\begin{array}{c}\text { Factor 2 } \\
(25 \%)\end{array}$ & $\begin{array}{c}\text { Factor 3 } \\
(12 \%)\end{array}$ & $\begin{array}{c}\text { Factor 4 } \\
(11 \%)\end{array}$ & $\begin{array}{c}\text { Factor 5 } \\
(10 \%)\end{array}$ \\
\hline Habit conception & $0.38^{\mathrm{b}}$ & $0.59^{\mathrm{b}}$ & 0.26 & -0.06 & -0.03 \\
Addiction conception & -0.01 & -0.20 & 0.21 & -0.04 & 0.10 \\
Sin conception & $0.53^{\mathrm{b}}$ & 0.14 & 0.25 & 0.17 & -0.27 \\
Disease conception & -0.14 & $-0.87^{\mathrm{b}}$ & -0.14 & 0.05 & -0.09 \\
Social etiology & 0.13 & 0.08 & $0.35^{\mathrm{b}}$ & $-0.40^{\mathrm{b}}$ & 0.11 \\
Physical etiology & -0.00 & -0.24 & -0.19 & $0.44 \mathrm{~b}$ & -0.04 \\
Inadequacy etiology & $0.64 \mathrm{~b}$ & 0.06 & -0.03 & -0.23 & 0.05 \\
Hereditary etiology & 0.00 & -0.16 & $-0.35^{\mathrm{b}}$ & 0.01 & -0.26 \\
Moral weakness etiology & $0.77^{\mathrm{b}}$ & -0.03 & -0.05 & -0.05 & 0.07 \\
Attitudes Index & $-0.71^{\mathrm{b}}$ & -0.21 & 0.09 & -0.14 & 0.05 \\
Social desirability & 0.01 & 0.12 & -0.01 & 0.25 & 0.05 \\
Age & 0.28 & -0.01 & $-0.62^{\mathrm{b}}$ & 0.14 & -0.18 \\
Education & $-0.61^{\mathrm{b}}$ & 0.09 & 0.21 & $-0.40^{\mathrm{b}}$ & 0.19 \\
Social class & 0.32 & -0.07 & 0.07 & $0.42^{\mathrm{b}}$ & 0.09 \\
Contact with alcoholics & -0.04 & 0.00 & -0.08 & -0.08 & $-0.69 \mathrm{~b}$ \\
Personal consumption & -0.02 & 0.08 & 0.29 & -0.08 & -0.02 \\
\hline
\end{tabular}

aPercentage of variance accounted for by each factor is given in parentheses.

b Loading $>0.35$.

ships between variables. Factor analysis was carried out using principal factoring with iterations to extract the initial factors. The minimum eigenvalue was set at 1.0. Five factors were extracted and rotated to an oblique terminal solution with a delta value of zero. The results of this analysis are given at Table 4 .

As can be seen from Table 4, Factor 1 emerges as a general factor with six variables showing high loadings. The moral weakness item and the "alcoholism as sin" item show high positive loadings on this factor. The Attitudes Index also shows a high negative loading. It can be seen that number of years of education appears to show a strong relationship with rejection of moral conceptions and the expression of humanitarian attitudes. The illness/disease variable has a very low loading on Factor 1. However, examination of Factor 2 reveals that the disease item loads very highly on this factor. Given that the "habit" item is the other variable showing a high loading on Factor 2, it is possible to view this factor as an "ill/not ill" dimension. The factor correlation matrix revealed that Factors 1 
and 2 did not show a substantial intercorrelation $(r=0.12)$. Thus it would appear that, for the present sample, expressing humanitarian attitudes toward alcoholics is largely independent of whether alcoholism is conceptualized as a disease.

\section{DISCUSSION}

The discussion is structured according to the fours aims of the study described in the Introduction.

1. Since almost $70 \%$ of the sample endorsed a disease conception of alco holism, this would suggest that, in the northeast section of Scotland at least, the widespread publicity campaign to have alcoholism recognized as a disease has met with considerable success. This finding is comparable with the figures re ported in the American attitudes literature (Haberman and Sheinberg, 1969; Mulford and Miller, 1964).

2. The American literature has demonstrated fairly consistently that, al though there has been a dramatic rise in the numbers accepting a disease view, a corresponding decline in moral weakness conceptions has not occurred. Al though we do not have the benefit of suitable previous studies to reliably assess whether this historical pattern has occurred in Scotland or Britain generally, the fact that relatively few respondents $(27.5 \%)$ endorsed a moral concep tion would suggest that there has in fact been some decline in the moral weak ness view in Britain. Roizen (1978) has argued that the nature of the presen tation of the disease concept may actually encourage moral conceptions, so that those accepting a disease concept will be more likely to endorse or ex press these views. Although two American studies have reported such findings (Orcutt, 1976; Room, 1972), the present study has not upheld this hypoth esis. Respondents who endorsed the disease concept were more likely to reject a "moral weakness" view than those who did not endorse it.

3. There was no evidence from this study that endorsing the disease con cept of alcoholism was associated with higher scores on a measure of "social desirability." The discrepancy between this finding and that of Tolor and Tamerin (1975) could possibly be explained by the highly restricted nature of the sample used in the latter study or by the fact that a shortened form of the Social Desirability Scale was used in the present study.

4. Previous public attitudes research has been largely characterized by attempts to monitor the extent to which the notion "alcoholism is a disease" has become inculcated into the public mind. However, the findings from the present study suggest that such efforts may be little more than academic exer cises. Accepting or rejecting a disease view would appear to play little part in determining whether the public believes alcoholics are entitled to sympathy or should be offered help that involves public funding. 
These findings clearly challenge the widespread assumption that the disease concept is a powerful vehicle for the promotion of humanitarian attitudes. A study by Crawford (1981) tackled this issue from a different perspective. In a comparison of attitudes toward alcoholics and compulsive gamblers, it was reported that, although there was a large difference in the extent to which the public saw these conditions as a disease or illness, the public did not differ in the extent to which they considered alcoholics or compulsive gamblers to be entitled to treatment. These results can be viewed as consistent with the present findings as they illustrate that the illness label need not convey an advantage in the attempt to engender positive attitudes.

Given that acceptance/rejection of a disease view does not appear to be related to attitudes toward alcoholics, the question arises as to what factors are important in shaping such attitudes. The high correlation observed here between believing that alcoholism is a result of moral weakness and expressing "unsympathetic" attitudes to alcoholics suggests that an important factor is the extent to which noncondemning views of etiology are held. This century has witnessed a growth in noncondemning humanitarian attitudes toward most deviant groups (Schneider, 1978). It could be argued that it is this general trend that has largely accounted for the positive historical change in attitudes to alcoholics. It could also be argued that contemporary individual differences in attitudes to alcoholics will be largely determined by the extent to which individuals hold this general "humanitarian world view" rather than whether they consider alcoholism to be a disease. In other words, attitudes to other deviant groups (including those who have not acquired the illness label) will be a better predictor of attitudes toward alcoholics than will acceptance/rejection of a disease view. This hypothesis is open to empirical test and is currently being investigated.

\section{ACKNOWLEDGMENTS}

This research was carried out while the first author (J.C.) was a member of the Addictive Behaviours Research Group and was supported by a grant from the Manpower Services Commission. We are grateful to Frances Loots for help in collecting data and to Ian Robertson for helpful advice and suggestions.

\section{REFERENCES}

CRAWFORD, J.R. Public attitudes towards alcoholics and compulsive gamblers: Implications for the disease concept of alcoholism. B.Sc. dissertation, University of Stirling, Department of Psychology, 1981.

CROWNE, D.P., and MARLOWE, D. A new scale of social desirability independent of psychopathology./. Consult. Clin. Psychol. 24: 349-354,1960. 
HABERMAN, P.W., and SHEINBERG, J. Public attitudes toward alcoholism as an illness. Am. J. Public Health 59: 1209-1216,1969. JELLINEK, E.M. The Disease Concept of Alcoholism. New Haven, CT: Hillhouse Press,

1960. KELLER, M. Problems with alcohol: An historical perspective. In W.

Filstead, J. Rossi,

and M. Keller (eds.), Alcohol and Problems. Cambridge, MA: Ballinger, 1976.

KENDELL, R. Alcoholism: A medical or a political problem? Br. Med. J. 1: 367-371, 1979.

MARCUS, A. Alcoholism Questionnaire. Toronto, Canada: Alcohol and Drug Addiction Research Foundation, 1963. MULFORD, H.A., and MILLER, D.E. Measuring public acceptance of the alcoholic as a sick person. Q. J. Stud. Alcohol 25: 314-323,1964.

ORCUTT, J.D. Ideological variation in the structure of deviant types: A multivariate comparison of alcoholism and heroin addiction. Soc. Forces 2: 419437,1976. PATTISON,

E.M. Comment on "The alcoholic game." Q. J. Stud. Alcohol 30: 953-956, 1969. ROIZEN, R. Comment on the Rand Report. In DJ. Armor, M. Polich, and

H. Stambul

(eds.), Alcoholism and Treatment. New York: Wiley, 1978. ROOM, R. Comment on

"The alcohologists' addiction." Q. J. Stud. Alcohol 33: 1049-

1059,1972. ROOM, R. Sociology and the disease concept of alcoholism. In Y.

Israel (ed.), Research

Advances in Alcohol and Drug Problems, Vol. 7. New York: Plenum Press, 1983.

SCHNEIDER, J.W. Deviant drinking as disease: Alcoholism as a social accomplishment. Soc. Probl. 25: 361-372,1978.

TO LOR, A., and TAMERIN, J.S. The Attitudes toward Alcoholism Instrument: A measure of attitudes toward alcoholics and the nature and causes of alcoholism. Br.J. Addict. 70: 223-231,197'5. 